\title{
EDITORIAL: STATEMENTS OF INTENT
}

\author{
Christopher Fox
}

As Edwin Starr didn't quite sing in 1970, 'Manifestos, what are they good for? Absolutely nothing'. Like war, manifestos are a call to arms, a radical intervention, an attempt to cut across the course of history, and in this issue of TEMPO we are featuring a series of articles which have at least something of the texture of manifestos.

Some manifestos - Karl Marx's Manifesto of the Communist Party (1848) is perhaps the best example - combine some sort of analysis within their proposed agenda for change; others simply launch into their action plan. 'BLAST First (from politeness) ENGLAND' begins the Vorticist manifesto, first published in Wyndham Lewis's journal BLAST in June 1914, its vehemence bursting through the constraints of conventional typography. Perhaps because its authors were Danish film-makers, the Dogme 95 manifesto is more practical, its first commitment being that 'Shooting must be done on location. Props and sets must not be brought in (if a particular prop is necessary for the story, a location must be chosen where this prop is to be found)'.

In this issue Matthew Shlomowitz offers analysis as a means of locating 'where we are now' because unless we know where we are it's pointless trying to plot a path into the future. Kate Moore presents what appears to be a history of aspects of her recent compositional work; it is, however, also a manifesto for a deeply personal craft, a way of being a maker of all sorts of things, not just music. Atli Ingólfsson writes about the many layers of practice that form any theatrical act and in so doing reaches the conclusion that if 'theatre is the future of music, and music the future of theatre, then opera can be the field of their necessary symbiosis'.

Back to Edwin Starr's 'War': after asking 'what is it good for?' he goes on to suggest that, like a manifesto, it causes 'unrest within the younger generation, induction then destruction'. Wyndham Lewis's Vorticist manifesto, like Marinetti's 1909 Futurist manifesto ('We will glorify war - the world's only hygiene') of which it is an echo, is as excited by the prospect of destruction as by any sort of induction into new modes of thought, and in our current clickbait era social media constantly invite us to trash ideas, opinions, reputations. David Pocknee's Twitter account @ composeradvice uses the brevity of the tweet as a means of framing a series of observations about the state of new music today. Inductive or destructive? You decide.

At TEMPO we are making a manifesto commitment of our own. In an attempt to support all those people who are working to achieve greater diversity in the music world we have decided that in future we will not review concerts or recordings where a mixed programme represents only one gender. In other words, if you are an all-male ensemble with an all-male programme we will not review your work. There may be exceptions but until they come along we don't know what they might be. 
It was with great sadness that we heard of the death of the composer Klaus K. Hübler (1956-2018). Hübler was born in Munich, and from the late-1970s he established a reputation as a composer of fiercely complex scores. At first sight these seemed to suggest a close relationship with the music of Brian Ferneyhough, with whom Hübler studied, but the density of Hübler's notation is not the product of an elaboration of detail. Instead it represents a counterpoint between all the different actions by which a performer can call sound into being. 'De-coupling' is the term often used by those who followed Hübler's example but in his music every aspect of the music-making is intimately linked. The result, in a work such as Opus breve (1987) for solo cello, is music in which instrument, performer and composer seem to be constantly sparking ideas off one another, the three staves of the score barely able to contain the proliferation of possibilities.

Serious illness in 1989 made compositional work impossible for six years but when Hübler returned to composition it was with the same inventiveness as before, the music ever more surprising and extraordinary. Hübler was also a perceptive writer on other composers' music, Stockhausen and Cage being particular enthusiasms. We have lost not only a truly original composer and musical thinker but also a man of great charm and generosity. 